\title{
Trend Analysis of Exercise Content on the Rings Final in the 1st Youth Olympic Games
}

\author{
Yoon-Soo $\mathrm{Han}^{1} \cdot$ Oh-Seok Kwon ${ }^{2}$ \\ ${ }^{1}$ Department of Physical Education, College of Teachers, Kyungpook National University, Daegu, Korea \\ ${ }^{2}$ Department of Physical Education, Deajeon Geojeong Middle School, Daejeon, Korea \\ Received 28 January 2011; Received in revised form 7 February 2011; Accepted 15 March 2011
}

\begin{abstract}
The Youth Olympic Games(YOG) is an international multi-sport event first held in Singapore from August 14 to August 26, 2010. The idea for such an event was introduced by International Olympic Committee(IOC). The Federation of International Gymnastics(2009) designed the Code of Points and regulates for junior gymnastics at this time. The purpose of this study was to give crucial information and adapt to coaches and junior gymnasts at the time of changing code rapidly. For this study, The eight finalists rings exercise at the 1st Youth Olympic Games was recorded using a digital camcoder. The exercise contents analysis of rings was carried out by an experienced international judge using Code of Points(FIG, 2009). The C elements in various difficulties were performed the highest frequency. The elements group I was the most frequently performed in overall difficulties. Moreover, All the gymnasts performed the elements of the Jonasson and Yamawaki in Group I. Therefore, junior gymnasts need to consider Jonasson and Yamawaki elements correctly in elements group I. The 1st ranked ROU(132) gymnast performed high difficulty value for his routine with the highest $\mathrm{E}$ score (9.050). The average of D score were 5.125. In the E scores, 8th USA(140) gymnast received the lowest E score of 8.15, 5th MGL(127) gymnasts received the fewer E score of 8.475. Coaches and junior gymnasts should try to increase D score above 5.125 by higher swing elements in Group I and II as well, decrease deduction of elements in exercise contents.
\end{abstract}

Keywords : Rings, Exercise Content, Difficulty Score, Execution Score

\section{Introduction}

The Youth Olympic Games(YOG) is an international multi-sport event and was first hosted by Singapore from August 14 to August 26, 2010. The games are planned to be held every four years in staggered summer and winter events consistent with the current Olympic Games format. The Youth Olympic Games will feature athletes between the ages of 14 and 18. The idea for such an event was introduced by International Olympic Committee(IOC) president Jacques Rogge in 2001(International Olympic Committee, 2007).

Corresponding Author : Oh-Seok Kwon

Department of Physical Education, Deajeon Geojeong Middle School,

120 Geojeong-dong, Seo-Gu, Deajeon, Korea

Tel : +82-42-528-9053 / Fax : +82-42-528-9057

E-mail : kosme@hanmail.net
Artistic gymnastics includes multiple events; six for men(floor exercise, pommel horse, rings, vault, parallel bars, and horizontal bar) four for women(vault, uneven bars, balance beam, floor exercise) and, in each event, gymnasts perform routines comprising of many skills(Prassas, Kwon \& Sands, 2006). An exercise on the rings is composed of swing, strength and hold parts in approximately equal portions. These parts and combinations are executed in a hang position, a support position, the handstand position, and execution with straight arms should be predominant. Contemporary gymnastic exercises are characterized by transitions between elements of swing and strength or the reverse. The swinging of the cables and the crossing of the cables are not permitted. Gymnastics exercise composition on the rings is performed in five groups with kip and swing elements, swings to handstand(2 sec), swings to strength hold elements(not L-sits, 2 
sec.), strength elements and hold elements( $2 \mathrm{sec})$, and dismounts. The Code of Points has been changed every 4 years. The changes stemmed from the judging controversy at the 2004 Olympics in Athens, which brought the reliability and objectivity of the scoring system into question and fuelled arguments that execution had been sacrificed for difficulty in artistic gymnastics(Federation of International Gymnastics, 2009).

The Code of Points is subject to a review every four years, to encompass technological developments, coach and gymnast innovation and increasing levels of ability(Bruggemann, Cheetham, Alp \& Arampatzis, 1994). Since the 2004 Athens Olympic Games, a Code of Points system was introduced in 2005 to replace the old scoring system for all events. The perfect 10 as a maximum score was abolished in favor of an open-ended system, designed to allow greater separation of gymnasts's scores. One panel of difficulty judges start from 0 , adding points for requirements, difficulty and connections. A second panel of execution judges start from 10.0, and deducts for execution and artistry. The final score is determined by adding the difficulty score and the execution score(Han, 2010; Han \& Jung, 2010).

The FIG designed the Code of Points and regulates for junior gymnasts in 2009 . The difficulty score will include by additional difficulty value of 8 elements, the best 7 , but maximum 4 elements for the same element group, inside the best counting plus the value of the dismount.

According to the revised Code of Points on the rings(FIG, 2009), repeated elements can not contribute to the " $\mathrm{D}$ " score. On rings, this rule is extended so that the same final strength hold position may be shown at most twice if the position was achieved from a different code number element(FIG, 2009).

The rings exercise by the revised Code of Points emphasizes the variety of exercise construction. Accordingly, this study is very valuable in adapting exercise content on the rings for junior gymnasts.

Studies have been conducted on artistic gymnastics exercises to clarify the start value, difficulty score and bonus score(Han, 2004, 2007; Jung, 2008; Nam, 2009; Kim, 2010; Kim, Nam \& Kwon, 2009; Kim \& Park, 2010; Kim \& Roh, 2003). Among them, Nam(2009) studied the score distribution of the men's floor exercise in 2008 Beijing Olympic Games. Samuels, Irwin, Kerwin \& Gittoes(2009) investigated and quantify the trend in Kovacs release and re-grasp skills and to evaluate the development of the Kovacs within the Code of Points. On the other hand, Prassas et al.(2006) biomechanical research on the rings in artistic gymnastics have been presented kinematic and kinetic profiles of giant swings(reaction forces; body configuration; optimization solutions to remove residual swing in the handstand), dismounts(twisting techniques and segmental contributions), and double salto without releasing the rings(centre of mass velocity and displacement; timing). However, studies have yet to be carried out on analysis of the exercise contents on the rings regarding junior gymnastics since the revised Code of Points. The purpose of this study was to analyze trend of exercise content and construction on the rings, which is regarded as a crucial information for coaches and junior gymnasts.

\section{Methods}

\section{Subjects}

Subjects are eight male gymnasts at the rings final in the 1st Youth Olympic Games in Singapore(Table 1).

Table 1. Rings final results

\begin{tabular}{ccc}
\hline Rank & Name & NOC Code \\
\hline \hline 1 & M.A. & ROU \\
2 & K.Y. & JPN \\
3 & A.N. & ESP \\
4 & S.O. & UKR \\
5 & G.E. & MGI \\
6 & K.D. & RUS \\
7 & Z.X & CHN \\
8 & G.J. & USA \\
\hline
\end{tabular}

\section{Data collection}

The author took part in the 1st Youth Olympic Games to collect data. The eight finalists rings exercise at the 1st Youth Olympic Games was recorded using a digital camcorder, which was positioned approximately $35 \mathrm{~m}$ away from the rings.

\section{Data analysis}

The final eight gymnasts rings exercise at the 1st Youth Olympic Games were reviewed using the video tape. The exercise contents analysis of rings was carried out by three international 
judges using Men's Code of Points(FIG, 2009). In order to analyze the pattern of difficulty(D2) in Rings exercise, all composition sheets for the Rings were considered. Date on Rings elements for the exercise routines were extracted and recorded in a Microsoft Excel spreadsheet. The data was conducted from the frequency and percentage using the SPSS version 17.0 statistical package.

\section{Results and Discussion}

\section{Analysis of Difficulties and Elements Group}

The type and difficulty of skills on still rings have rapidly changed over the last decade with swinging skills currently comprising a large part of gymnasts' routines. Research, however, has not progressed equally(Prassas et al., 2006). To our knowledge, there are no published information of the trend analysis of exercise content on the Rings. The present study, therefore, aimed to analyze trend of exercise content and construction on the rings.

Analysis of difficulties on the rings final are shown in(Table 2 , 3)(Figure 1, 2).

Difficulty values will count G 0.7, F 0.6, E 0.5 , D 0.4, C 0.3, B 0.2, A 0.1(FIG, 2009). However, there are no $G$ difficulty in the rings. All the gymnasts did not perform A difficulty in the overall skills performed. The $\mathrm{C}$ difficulty was the most frequently performed $57.81 \%$ of overall difficulties. The D, B, C, F difficulties were performed $25 \%, 10.94 \%, 4.69 \%$, and $1.56 \%$.

The 1st ranked ROU(132) gymnast performed higher difficulties of $1 \mathrm{E}, 2 \mathrm{D}$ and $5 \mathrm{D}$ elements(D score $=5.3)$ more than the other gymnasts. Furthermore, the 2nd Ranked JPN(122) gymnast performed a higher frequency of $1 \mathrm{E}, 2 \mathrm{D}$, and $4 \mathrm{C}$ elements(D score=5.2). On the contrary, the 5th ranked MGL(127) gymnast performed the highest difficulties of 1F, 3D, 4C elements(D score=5.5). However, the MGL gymnast showed a lower frequency of $\mathrm{E}$ score(8.475) more than the 1st ROU and JPN gymnasts. Consequently, junior gymnasts need to reduce the maximum deduction for getting high $\mathrm{E}$ score more than higher difficulties.

Analysis of element group on the rings final are shown in< Table 2, 3>, <Figure 3>. Each apparatus has four element groups designated as I, I, III, IV, and except floor exercises, a dismount group designated as $\mathrm{V}$. In his exercise, the gymnast must include at least one element from each of the four elements. Each element group fulfillment is awarded with 0.5 points by $D$ jury(FIG, 2009).

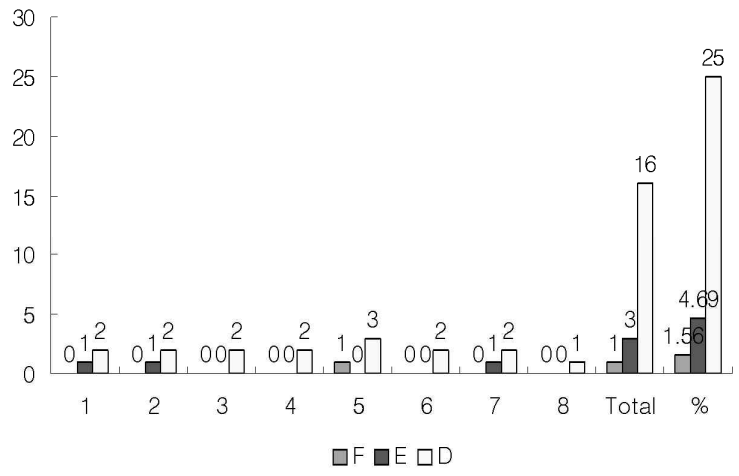

Figure 1. Number of difficulty F, E, D

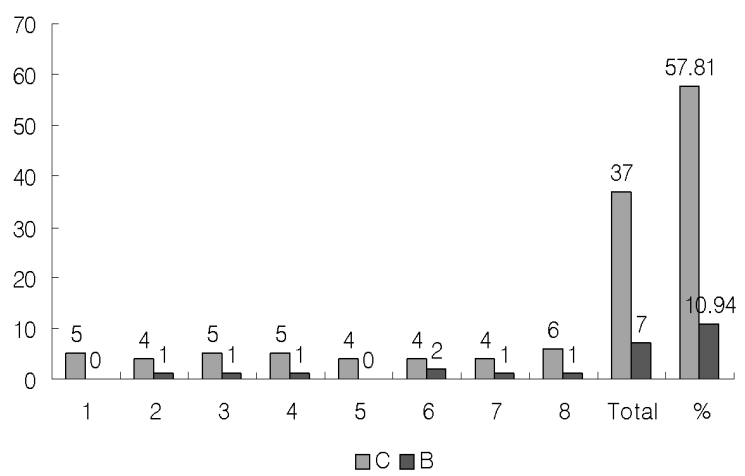

Figure 2. Number of difficulty C, B

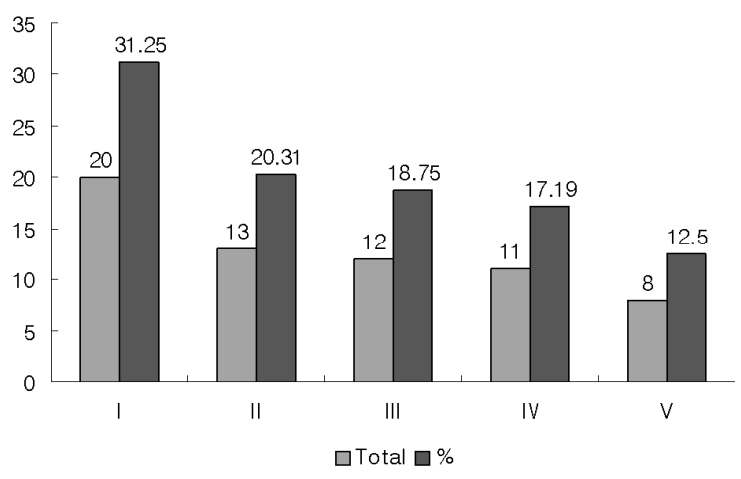

Figure 3. Number of element group

The elements group(EG) were shown EG I (kip and swing elements) $31.25 \%$, EG П(swings to handstand) $20.31 \%$, EG III (Swing to strength hold elements) $18.75 \%$, EG IV(strength elements and hold elements) $17.19 \%$, and EG V(dismount) $12.5 \%$. The elements group I was the most frequently performed in overall difficulties. Moreover, All the gymnasts performed the elements of the Jonasson and Yamawaki in Group I . Jonasson and Yamawaki are swing elements. These skills are very useful connection the Yamawaki to Jonasson on the Rings. Therefore, coaches and junior gymnasts need to construct their routines by Jonasson and Yamawaki elements in elements group I 
Table 2. Analysis of the exercise content(1)

\begin{tabular}{|c|c|c|c|c|c|c|c|c|c|}
\hline \multicolumn{5}{|c|}{ Rank 1, ROU(132) } & \multicolumn{5}{|c|}{ Rank 2, JPN(122) } \\
\hline No & Element & Group & Dif & Es & Element & Group & Dif & Es & $\mathrm{Pe}$ \\
\hline 1 & $\begin{array}{l}\text { Bwd. swing to } \\
\text { Swallow }\end{array}$ & III, 35 & $\mathrm{E}(0.5)$ & & $\begin{array}{l}\text { Bwd. swing to scale } \\
\text { straddled }\end{array}$ & III, 33 & $\mathrm{C}(0.3)$ & & \\
\hline 2 & Hirondelle & $\mathrm{IV}, 10$ & $\mathrm{D}(0.4)$ & & Press to hdst. & $\mathrm{IV}, 26$ & $\mathrm{~B}(0.2)$ & & \\
\hline 3 & $\begin{array}{l}\text { Bwd. swing to scale } \\
\text { straddled }\end{array}$ & III, 33 & $\mathrm{C}(0.3)$ & & $\begin{array}{l}\text { Double salto fwd. } \\
\text { stretched }\end{array}$ & I, 53 & $\mathrm{E}(0.5)$ & & \\
\hline 4 & Felge upward to hdst. & $\Pi, 3$ & $\mathrm{C}(0.3)$ & & Yamawaki & $\mathrm{I}, 51$ & $\mathrm{C}(0.3)$ & & \\
\hline 5 & Jonasson & $\mathrm{I}, 52$ & $\mathrm{D}(0.4)$ & & Bwd. swing to hdst. & II, 9 & $\mathrm{C}(0.3)$ & & \\
\hline 6 & Yamawaki & $\mathrm{I}, 51$ & $\mathrm{C}(0.3)$ & & Felge upward to hdst. & II, 3 & $\mathrm{C}(0.3)$ & & \\
\hline 7 & Bwd. swing to hdst. & П, 9 & $\mathrm{C}(0.3)$ & & Jonasson & I, 52 & $\mathrm{D}(0.4)$ & & \\
\hline 8 & $\begin{array}{l}\text { Double salto bwd. } \\
\text { stretched }\end{array}$ & $\mathrm{V}, 33$ & $\mathrm{C}(0.3)$ & & Balabanov & $\mathrm{V}, 16$ & $\mathrm{D}(0.4)$ & & \\
\hline Content & & $\begin{array}{l}2 \mathrm{I} / 2 \mathrm{I} / 2 \mathrm{II} / \\
1 \mathrm{IV} / 1 \mathrm{~V}\end{array}$ & $1 \mathrm{E} / 2 \mathrm{D} / 5 \mathrm{C}$ & & & $3 \underset{/ 1 \mathrm{I}}{2 \mathrm{I} / 1 \mathrm{II} / 1 \mathrm{IV}}$ & $1 \mathrm{E} / 2 \mathrm{D} / 4 \mathrm{C} / \mathrm{B}$ & & \\
\hline $\mathrm{Gs} / \mathrm{Ds} / \mathrm{Es}$ & & 2.5 & 2.8 & 9.050 & & 2.5 & 2.7 & 9.00 & \\
\hline SV & & & 5.3 & & & & 5.2 & & \\
\hline Total & & & 14.350 & & & & 14.200 & & \\
\hline \multicolumn{5}{|c|}{ Rank 3, ESP(114) } & \multicolumn{5}{|c|}{ Rank 4, UKR(139) } \\
\hline 1 & Hirondelle & $\mathrm{IV}, 10$ & $\mathrm{D}(0.4)$ & & Azarian & $\mathrm{IV}, 52$ & $\mathrm{D}(0.4)$ & & \\
\hline 2 & $\begin{array}{l}\text { Bwd. swing to scale } \\
\text { straddled }\end{array}$ & III, 33 & $\mathrm{C}(0.3)$ & & kip to cross & III, 45 & $\mathrm{C}(0.3)$ & & \\
\hline 3 & Felge upward to hdst. & П, 3 & $\mathrm{C}(0.3)$ & & Jonasson & I, 52 & $\mathrm{D}(0.4)$ & & \\
\hline 4 & Jonasson & I, 52 & $\mathrm{D}(0.4)$ & & Yamawaki & I, 51 & $\mathrm{C}(0.3)$ & & \\
\hline 5 & Yamawaki & I, 51 & $\mathrm{C}(0.3)$ & & $\begin{array}{l}\text { Bwd. swing to scale } \\
\text { straddled }\end{array}$ & III, 33 & $\mathrm{C}(0.3)$ & & \\
\hline 6 & Bwd. swing to hdst. & II, 9 & $\mathrm{C}(0.3)$ & & Press to hdst. & $\mathrm{IV}, 26$ & $\mathrm{~B}(0.2)$ & & \\
\hline 7 & Felge upward to hdst. & I, 26 & $\mathrm{~B}(0.2)$ & & Bwd. swing to hdst. & II, 9 & $\mathrm{C}(0.3)$ & & \\
\hline 8 & $\begin{array}{l}\text { Double salto bwd. } \\
1 / 1 \text { turn }\end{array}$ & $\mathrm{V}, 39$ & $\mathrm{C}(0.3)$ & & $\begin{array}{l}\text { Double salto bwd. } \\
\text { stretched }\end{array}$ & $\mathrm{V}, 33$ & $\mathrm{C}(0.3)$ & & \\
\hline Content & & $\begin{array}{l}3 \mathrm{I} / 2 \mathrm{I} / 3 \mathrm{II} / \\
1 \mathrm{IV} / 1 \mathrm{~V}\end{array}$ & $2 \mathrm{D} / 5 \mathrm{C} / 1 \mathrm{~B}$ & & & $2 \mathrm{I} / 1 \mathrm{\Pi} / 2 \mathrm{II} / 1 \mathrm{IV}$ & $2 \mathrm{D} / 5 \mathrm{C} / 1 \mathrm{~B}$ & & \\
\hline Gs/Ds/Es & & 2.5 & 2.5 & 9.150 & & 2.5 & 2.5 & 8.975 & \\
\hline SV & & & 5.0 & & & & 5.0 & & \\
\hline Total & & & 14.150 & & & & 13.975 & & \\
\hline
\end{tabular}


Table 3. Analysis of the exercise content(2)

\begin{tabular}{|c|c|c|c|c|c|c|c|c|c|c|}
\hline \multicolumn{6}{|c|}{ Rank 5, MGL(127) } & \multicolumn{5}{|c|}{ Rank 6, RUS(134) } \\
\hline No & Element & Group & Dif & Es & $\mathrm{Pe}$ & Element & Group & Dif & Es & $\mathrm{Pe}$ \\
\hline 1 & $\begin{array}{l}\text { Felge bwd. slowly } \\
\text { str. to swallow }\end{array}$ & $\mathrm{IV}, 48$ & $\mathrm{~F}(0.6)$ & & & Bwd. swing to cross & III, 39 & $\mathrm{C}(0.3)$ & & \\
\hline 2 & Nakayama & $\mathrm{IV}, 58$ & $\mathrm{D}(0.4)$ & & & Felge upward to hdst. & П, 3 & $\mathrm{C}(0.3)$ & & \\
\hline 3 & Azarian & $\mathrm{IV}, 52$ & $\mathrm{D}(0.4)$ & & & Bwd. swing to hdst. & ПI, 9 & $\mathrm{C}(0.3)$ & & \\
\hline 4 & $\begin{array}{l}\text { Bwd. swing to scale } \\
\text { straddled }\end{array}$ & III, 33 & $\mathrm{C}(0.3)$ & & & Jonasson & $\mathrm{I}, 52$ & $\mathrm{D}(0.4)$ & & \\
\hline 5 & Bwd. swing to hdst. & II, 9 & $\mathrm{C}(0.3)$ & & & Yamawaki & I, 51 & $\mathrm{C}(0.3)$ & & \\
\hline 6 & Jonasson & $\mathrm{I}, 52$ & $\mathrm{D}(0.4)$ & & & Press to hdst. & $\mathrm{IV}, 26$ & $\mathrm{~B}(0.2)$ & & \\
\hline 7 & Yamawaki & $\mathrm{I}, 51$ & $\mathrm{C}(0.3)$ & & & Bwd. swing to hdst. & I, 26 & $\mathrm{~B}(0.2)$ & & \\
\hline 8 & $\begin{array}{l}\text { Double salto bwd. } \\
\text { stretched }\end{array}$ & $\mathrm{V}, 33$ & $\mathrm{C}(0.3)$ & & & $\begin{array}{l}\text { Double salto bwd. } \\
\text { stre. } 1 / 1 \text { turn }\end{array}$ & $\mathrm{V}, 46$ & $\mathrm{D}(0.4)$ & & \\
\hline Content & & $\begin{array}{l}2 \mathrm{I} / 1 \mathrm{II} / 1 \mathrm{III} / \\
3 \mathrm{IV} / 1 \mathrm{~V}\end{array}$ & $1 \mathrm{~F} / 3 \mathrm{D} / 4 \mathrm{C}$ & & & & $\begin{array}{l}3 \mathrm{I} / 2 \mathrm{II} / 1 \mathrm{II} / \\
1 \mathrm{IV} / 1 \mathrm{~V}\end{array}$ & $2 \mathrm{D} / 4 \mathrm{C} / 2 \mathrm{~B}$ & & \\
\hline $\mathrm{Gs} / \mathrm{Ds} / \mathrm{Es}$ & & 2.5 & 3.0 & 8.475 & & & 2.5 & 2.4 & 8.925 & \\
\hline SV & & & 5.5 & & & & & 4.9 & & \\
\hline Total & & & 13.975 & & & & & 13.825 & & \\
\hline \multicolumn{5}{|c|}{ Rank 7, CHN(108) } & & \multicolumn{5}{|c|}{ Rank 8, USA(140) } \\
\hline 1 & kip to cross & III, 45 & $\mathrm{C}(0.3)$ & & & kip to cross & III, 45 & $\mathrm{C}(0.3)$ & & \\
\hline 2 & $\begin{array}{l}\text { Double salto fwd. } \\
\text { stretched }\end{array}$ & $\mathrm{I}, 53$ & $\mathrm{E}(0.5)$ & & & $\begin{array}{l}\text { Bwd. swing to scale } \\
\text { straddled }\end{array}$ & III, 33 & $\mathrm{C}(0.3)$ & & \\
\hline 3 & Yamawaki & $\mathrm{I}, 51$ & $\mathrm{C}(0.3)$ & & & Felge upward to hdst. & ПI, 3 & $\mathrm{C}(0.3)$ & & \\
\hline 4 & Jonasson & $\mathrm{I}, 52$ & $\mathrm{D}(0.4)$ & & & Bwd. swing to hdst. & П, 9 & $\mathrm{C}(0.3)$ & & \\
\hline 5 & $\begin{array}{l}\text { Bwd. swing to scale } \\
\text { straddled }\end{array}$ & III, 33 & $\mathrm{C}(0.3)$ & & & Jonasson & $\mathrm{I}, 52$ & $\mathrm{D}(0.4)$ & & \\
\hline 6 & Cross & $\mathrm{IV}, 14$ & $\mathrm{~B}(0.2)$ & & & Yamawaki & I, 51 & $\mathrm{C}(0.3)$ & & \\
\hline 7 & Bwd. swing to hdst. & П, 9 & $\mathrm{C}(0.3)$ & & & Press to hdst. & $\mathrm{IV}, 26$ & $\mathrm{~B}(0.2)$ & & \\
\hline 8 & $\begin{array}{l}\text { Double salto bwd. } \\
\text { stre. } 1 / 1 \text { turn }\end{array}$ & $\mathrm{V}, 46$ & $\mathrm{D}(0.4)$ & & & $\begin{array}{l}\text { Double salto bwd. } \\
1 / 1 \text { turn }\end{array}$ & $\mathrm{V}, 39$ & $\mathrm{C}(0.3)$ & & \\
\hline Content & & $\begin{array}{l}3 \mathrm{I} / 1 \mathrm{II} / 2 \mathrm{II} / \\
1 \mathrm{IV} / 1 \mathrm{~V}\end{array}$ & $\begin{array}{c}1 \mathrm{E} / 2 \mathrm{D} / 4 \mathrm{C} / 1 \\
\mathrm{~B}\end{array}$ & & & & $\begin{array}{l}2 \mathrm{I} / 2 \mathrm{II} / 2 \mathrm{III} / \\
1 \mathrm{IV} / 1 \mathrm{~V}\end{array}$ & $1 \mathrm{D} / 6 \mathrm{C} / 1 \mathrm{~B}$ & & \\
\hline $\mathrm{Gs} / \mathrm{Ds} / \mathrm{Es}$ & & 2.5 & 2.7 & 8.575 & & & 2.5 & 2.4 & 8.15 & \\
\hline SV & & & 5.2 & & & & & 4.9 & & \\
\hline Total & & & 13.775 & & & & & 13.050 & & \\
\hline
\end{tabular}


The 1st ranked ROU(132) gymnast performed the elements by 2 I, 2I, 2III, 1IV, 1V. The 2nd ranked JPN(122) gymnast performed the elements by $3 \mathrm{I}, 2 \mathrm{I}, 1 \mathrm{III}, 1 \mathrm{I}, 1 \mathrm{~V}$ group. All the gymnasts received the element group score of 2.5 .

All the gymnasts performed the swing to handstand element in group $\Pi$. Consequently, junior gymnasts should include more swing to handstand elements in order to be equal to the highest ranked gymnasts. It can be due to the fact that swing elements in group I and II lesser deduction than strength elements. According to revised Code of Points(FIG, 2009), all strength holds must be held for a minimum of 2 seconds. If they are not held, they will be not recognized by the $\mathrm{D}$ Jury for difficulty and elements group requirements. The elements that are not held will receive large deduction(0.3). Also, during any kind of hold position, the shoulders may not rise above the final hold position. If the shoulders rise above the final hold position, they will receive the number of deductions (up to $15^{\circ}=0.1,16^{\circ}-30^{\circ}=0.3$, over $30^{\circ}$, over $45^{\circ}=$ non-recognition). Therefore gymnasts must be held for a minimum of 2 seconds and angle less than $15^{\circ}$, when they perform any kind of strength elements.

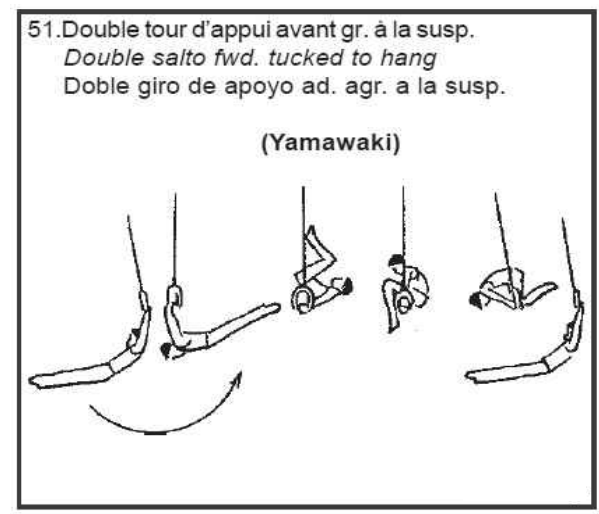

Figure 4. Element of Yamawaki

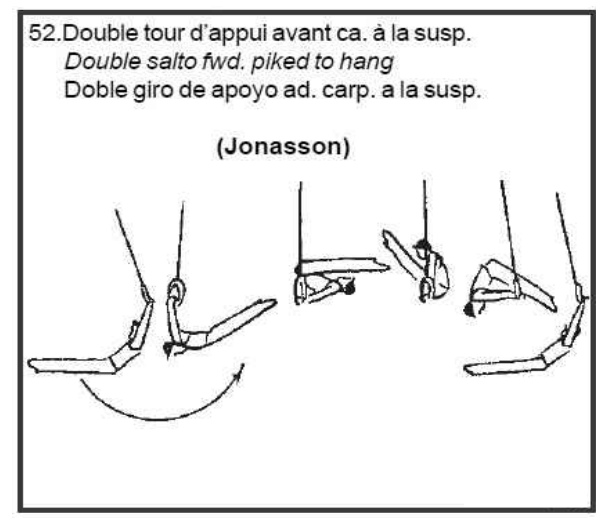

Figure 5. Element of Jonasson

\section{Analysis of D score, E score, and final score}

Analysis of difficulty score, execution score, and final score on rings are detailed in(Table 2, 3)(Figure 6, 7, 8).

In the D score, 5th ranked MGL 127(550) gymnast showed the highest score of 5.5, 1st ranked ROU(132) gymnasts showed a higher frequency of 5.2. The average D score were 5.125.

As a result, 1st ranked ROU(132) gymnast performed high difficulty value for his routine with the highest $\mathrm{E}$ score.

In order to get a high score, it is the most important exercise composition by high difficulties. however, gymnasts should consider deduction of difficulties due to inaccurate.

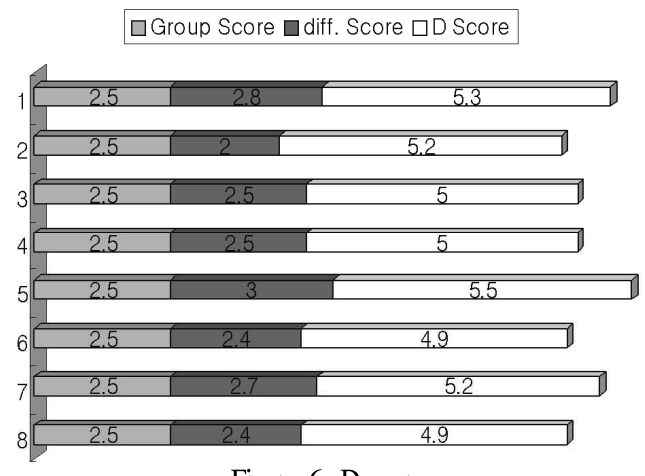

Figure 6. D score

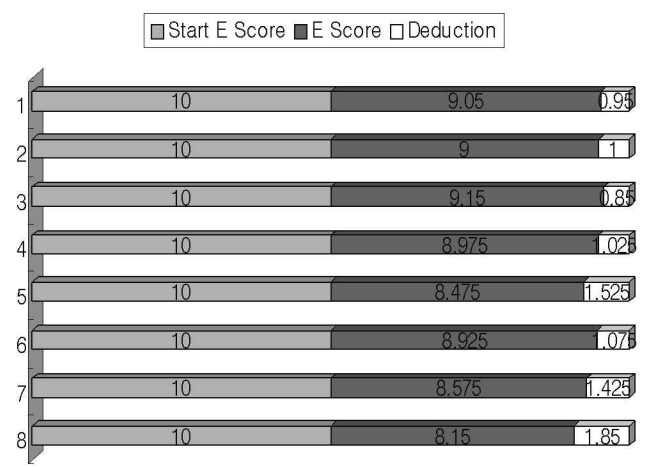

Figure 7. E score

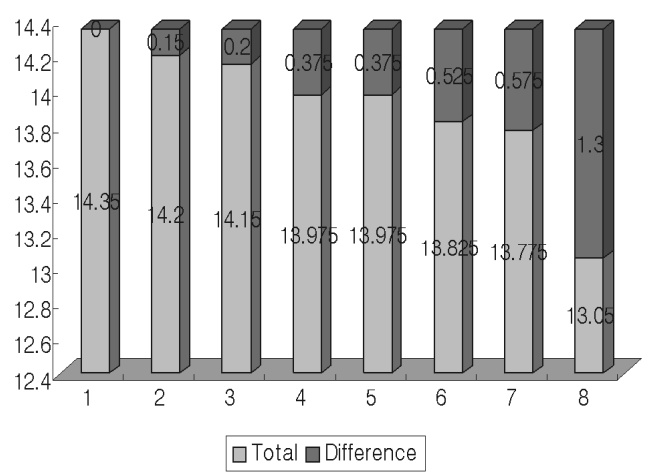

Figure 8. Difference of total score 
The execution score(E score) evaluates the exercise the execution and artistry of the routine. The $\mathrm{E}$ score is the most important score for getting good final score.

In the E scores, 8th USA(140) gymnast received the lowest E score of 8.15 , 5th MGL(127) gymnasts received the fewer E score of 8.475 .

On the contrary, the highest gymnasts's E scores ranged from 9.150 to 9.050. Therefor, in order to get a high E score, gymnasts need to performs their routine perfect and accurate without major deductions and errors. In the final results were differences 1.3 score between 1st ROU(132) gymnast and 8th USA(140) gymnasts. The junior gymnasts must perform accurate elements during the routine in order to raise the $\mathrm{E}$ score

This study provides a platform for future trend analysis of rings at major competition by junior Code of points.

\section{Conclusion}

The information obtained from the current study will be used to construct the exercise content on rings. The $\mathrm{C}$ elements in various difficulties were performed the highest frequency. The elements group I was the most frequently performed in overall difficulties. Moreover, All the gymnasts performed the elements of the Jonasson and Yamawaki in Group I. Therefore, junior gymnasts need to consider Jonasson and Yamawaki elements correctly in elements group I. The 1st ranked ROU(132) gymnast performed high difficulty value for his routine with the highest $\mathrm{E}$ score(9.050). The average of D score were 5.125.

In the E scores, 8th USA(140) gymnast received the lowest E score of $8.15,5$ th MGL(127) gymnasts received the fewer E score of 8.475 .

Coaches and junior gymnasts should try to increase D score above 5.125 by higher swing elements in Group I and II as well, decrease deduction of elements in exercise contents. This study can be useful to coaches and junior gymnasts for exercise construction.

In order to get a high score, it is the most important exercise composition by high difficulties. however, gymnasts should consider deduction of difficulties due to inaccurate.

\section{Acknowledgments}

The authors would like to thank the Singapore gymnastics for help.

\section{Reference}

Bruggemann, G. P., Cheetham, P., Alp, Y., \& Arampatzis, D. (1994). Approach to a biomechanical profile of dismounts and release and regrasp skills of the high bar. Journal of Applied Biomechanics, 18, 332-344.

Federation of International Gymnastics(2009). Code of Points, Artistic Gymnastics for Men. Switzerland: FIG.

Han, Y. S.(2004). Analysis on performances of world excellent gymnastics in horizontal bar. The Korean Journal of Physical Education, 43(3), 325-334.

Han, Y. S., \& Choi, J. H.(2007). Analysis on the performances of the pommel horse by change of gymnastics's code of points. The Korean Journal of Physical Education, 46(2), 171-180.

Han, Y. S.(2010). Trend analysis of exercise content on the parallel bars final in the 2009 world artistic gymnastics championships. The Korean Journal of Physical Education, 19(1), 1033-1041.

Han, Y. S., \& Jung, J. S.(2010). Analysis on the deduction variable, deduction weight, and landing success rate of dismount on the parallel bars in the 2008 Beijing Olympic Games. The Korean Journal of Sport Science, 19(2), 1367-1375.

International Olympic Committee(2007). Youth Olympic Games. www.olympic.org.

Jung, I. G.(2008). The study on the world medal list gymnastics in floor exercise technique trend. The Korea Journal of Sports Science, 17(3), 203-213.

Kim, M. C., \& Roh, Y. T.(2003). Research on change of exercise contents and value points vault at the top class in the world. The Korean Journal of Physical Education, 42(1), 191-201.

Kim, D. H., Nam, H. W., \& Kwon, T. W.(2009). Research on the trend of parallel bars technique in world men's gymnastics competition. The Korea Journal of Sports Science, 18(4), 1265-1274.

Kim, D. H.(2010). A performance analysis of beijing olympics floor exercise gymnasts. The Korea Journal of Sports Science, 19(1), 113-125.

Kim, D. H., \& Park, H. U.(2010). Analysis on performance contents of the parallel bars on the male's gymnastics of 1st Japan Cup Game. The Korea Journal of Sports Science, 19(4), 1423-1433. 
Nam, S. G., \& Han, C. S.(2004). Comparison and analysis on the value points and the degress of perfection for each event among elite gymnastics. The Korean Journal of Physical Education, 43(5), 887-901.

Nam, S. G.(2009). An analysis on the score distribution of the man's floor exercise in the 2008 Beijing Olympic Games. The Korea Journal of Sports Science, 18(1), 1073-1081.

Prassa, S. G., Kwon, Y. H., \& Sands, W. A(2006). Biomechanical research in artistic gymnastics: A review. Sports Biomechanics, 5(2), 261-291.

Samuels, M., Irwin, G., Kerwin, D., \& Gittoes, M.(2009). Trend Analysis of Complex Release and Re-grasp Skills on the High Bar. Proceedings of the 27th International Symposium on Biomechanics in Sports. Limerick: Ireland, 3439-3443. 